\title{
Diagnostische Notizen
}

Springende Mydriasis bei einem gesunden 7 jährigen Mädchen.

Sanitätsrat Dr. E. Crømer-Cottbus sah bei einem Kinde, das ihm in seiner Tätigkeit als Schularzt vorgeführt wurde, folgendes:

Wenn das Kind den Beobachter fixierte, sah man zunächst eine erhebliche Mydriasis einer Seite. Bei völlig gleichbleibender Blick-richtung seitens des Kindes trat nach kurzer Zeit Verengerung der er-weiterten Pupille und eine fast völlige Erweiterung der anderen ein. Eine Gleiehmäßigkeit in diesem Spiel bezüglich der Dauer der Erweiterung einer Pupille war nicht zu bemerken, es erschien unregelmäßig, war auch an einzelnen Tagen ganz verschieden.

Die Untersuchung ergab: Das Kind ist seinem Alter entsprechend entwickelt, abgesehen von geringer Lymphdrüsenschwellung am Halse gesund, war auch nie ernstlich krank.

Die Augen sind in geringem Grade übersichtig gebaut, sonst regel-recht und $\Lambda$ veisen normales Sehvermögen auf. Reflektorische und konsensuelle Pupillenreaktion regelreclit. Bei der Konvergenzreaktion verengern sich beide Sehlöeher gleichmäßig; bei längerem Lesen tritt das beschriebene Pupillenspiel auf.

Den Eltern des Kindes war die Augenveränderung schon seit längerer Zeit aufgefallen.

Verf. sah das klinische Bild zum ersten Male in seiner Praxis. Die Durchsicht der Literatur ergab Cramer keine für seinen Fall ausreichende Erklärung.

Von neurologiseher Seite wird dem Phänomen vielfach eine un-günstige prognostische Bedeutung für schwere organische Xerven-störungen zugesprochen bezw. für Myelitis des Halsmarks oder mindestens Xeurasthenie, wenn Pupillenstarre fehle.

Kasuistische Mitteilungen von augenärztlicher Seite nahmen für einzelne Fälle meist abnorme Oculomotorius-Reizung oder -Erkrankung an, bezw. eine Reizung des Sympathikus-Xerven. Alle diese Erk, lärungen passen nicht zu Cramers Fall, in dem sämt-liche Äste des Oculomotorius durchaus regelrecht funktionierten.

Aus den Grenzgebieten.

87

Verf. kann keine einwandfreie Erklärung für seinen Fall spontaner springender Mydriasis geben. Er wird das Kind weiter beobachten, weist aber darauf hin, daß es Menschen gibt, welche die springende Mydriasis willkürl·'ch hervorbringen können, daß es zuweilen also gar keiner eigentlich krankhaften Reize bedart. (Der Fall des in Deutsch-land gewerbsmäßig herumreisenden Mannes mit springenden Pupillen, der nach Verf. anscheinend stark mit Anhalten des Atems arbeitet, so daß offenbar eine veränderte Blutverteilung, also Kaliberschwan-kungen der feinen Hirngefäße, die Ursache der Erweiterung waren.) (Klin. Monatsbl. f. Augenheilk. 1911. Neue Folge XL Bd. S. 201.) Junius.

Aus den Grenzgebieten.

nv.. Bad: Über Pupillenstarre bei multipler Sklerose. Neurol. Zentralbl. 1911. S. 586. 
Fall 1. 38 jähriger Arbeiter, der nie geschlechtskrank war. Früher starker Po1/8s. $\lambda 7$ or 15 Jahren Kopfverletzung.

Yov 2 Jahren Doppelsehen. Seit 1 Jahre Verschlechterung der Sprache, Unsicherheit in den Händen und Wackeln des Kopfes. Zeit-weise Kopfscbmerzen.

Objektiv: Euphorische Stimmung, erhaltene Intelligenz. Zittern des Kopfes beim Sprechen.

Verlangsamte, abgehackte Sprache.

Pupillen gleich, mittelweit, lichtstarr, aber auf Konvergenz reagie-rend. Keine Doppelbilder, kein Nystagmus. Temporale Abblassung der Papillen.

In den Armen leichtes,Intentionszittern. An den Beinen: Knie-phänomene und

Achillessehnenreflexe gesteigert. Kein Fußclonus, Babinsky, Oppenheim. Bauchdeckenreflexe fehlen.

Wassermann negativ.

Globulingehalt und Lymphozytengehalt nicht geprüft.

Fall 2. 59 jähriger Kaufmann. Als Kind Bettnässen. Geschlecht-liche Infektion negiert. Seit 30

Jahren rückenmarkskrank. Außerdem Neuralgic im 2. linken Trigeminusast.

Objektiv: Intelligenz und Gedächtnis geschwächt. Pupillen eng und lichtstarr.

Konvergenzreaktion erhalten.

Augenbewegungen frei. Kein Nystagmus. Augenhintergrund ohne Besonderheiten.

Sprache skandierend. In den oberen Extremitäten leichte Unsicherheit bei Zielbewegungen.

An den Beinen doppelseitige spastische Parese mit gesteigerten Sehnenreflexen und positivem

Babinsky. Spastischer Gang.

Abdominalreflexe nicht auszulösen. Erschwerung der Urin-entleerung.

W. Wassermann im Blut negativ.

Verf. halt die Diagnose multiple Sklerose in beiden Fallen fürsicher bewiesen. . Hübner-

Honn. 